\title{
Adaptive Fuzzy Decision Tree with Dynamic Structure for Automatic Process Control System of Continuous Cast Billet Production
}

\author{
I.I. Matsko ${ }^{1}$, O.S. Logunova ${ }^{2}$, V.V. Pavlov ${ }^{3}$, O.S. Matsko ${ }^{4}$ \\ ${ }^{\prime}$ (A post-graduate student, Dept. of computer engineering and applied mathematics, \\ FSBEI of HPE "Magnitogorsk state technical university named after G.I. Nosov", Russian Federation) \\ ${ }^{2}$ (Doctor of Technical Science, Professor, Dept. of computer engineering and applied mathematics, \\ FSBEI of HPE "Magnitogorsk state technical university named after G.I. Nosov", Russian Federation) \\ ${ }^{3}$ (A senior engineer of the electric steelmaking laboratory, \\ OJSC «Magnitogorsk metallurgical plant», Russian Federation) \\ ${ }^{4}$ (A candidate for a master's degree, Dept. of computer engineering and applied mathematics, \\ FSBEI of HPE "Magnitogorsk state technical university named after G.I. Nosov", Russian Federation,
}

ABSTRACT : - The article outlines the results of adaptive fuzzy decision tree development with dynamic structure for automatic process control system of continuous cast billet production. The authors described the structure, mathematical representation as well as adaptation algorithms and structure dynamics.

Keywords: - adaptive fuzzy decision tree with dynamic structure, automatic process control system, decision tree

\section{INTRODUCTION}

At present computer-aided decision making systems for complex multiphase manufacturing processes are being developed very intensively [1,2]. The complex nature of these processes requires the development of a cascade control circuit when parameter values are transferred from one production stage to another one. The technology of continuous cast billet production including steelmaking, steel refining and continuous casting can be considered as a multiphase manufacturing. Despite a great number of papers dealing with the study of the technological processes mentioned above, there are still some urgent problems to be solved [3]:

- data feedback is provided only for the organizational manufacturing structure which is unable to influence the manufacturing practice;

- the current control system lacks algorithms which make it possible to carry out real time monitoring of technology changes within one batch on the basis of the data gathered in the integrated data bank;

- there are no decision making algorithms based on the technological information about the process behavior and product quality.

The measure of stability of a number of heats is the quality of the final product. In this paper by the quality of the final product we mean the degree of internal macrodefects development of a billet. Macrodefects are formed due to the factors influencing liquid metal or a solidifying billet on all production stages. Among such factors one can mention the structure of raw materials (ratio of burden materials for steel-melting furnaces), metal temperature during tapping, content of chemical elements in steel, billet withdrawal rate, coolant consumption, etc. [4]. Development of multifactor relationships for predictable final product quality is unpractical as such relationships will contain some unquantifiable factors as well as factors of different nature and the value range of these factors might differ from each other hundreds or thousands times, etc. Besides the increase of the empirical model size does not improve the accuracy of result prediction [5].

Some theories and methods have been developed which make it possible to make decisions in complex processes on the basis of decision trees. The methods of decision making on the basis of tree-type structures offer the following advantages [6, 7]: fast learning process; generation of rules in the fields where experts find it difficult to give form to their knowledge; intuitive classification model; steady operation of the method even in case of violation of tentative assumptions included in the model; an ability to process a body of information without any special preparation procedures; high computational scalability.

The subject of the research is the processing chain of continuous cast billet production which includes electric arc steel-making furnaces, ladle furnace units, billet continuous casting machines of radial and curved types operating in the electric steel-making shop of OJSC «Magnitogorsk metallurgical plant».

The authors aimed to study the information support, mathematical support and software of the second level automatic control system of continuous cast billet production. 


\section{The STRUCTURE OF THE ADAPTIVE FUZZY DECISION TrEe WITH DYNAMIC STRUCTURE}

In order to provide feedback in the automatic control system of continuous cast billet production the authors developed adaptive fuzzy decision tree with dynamic structure. The aim of tree-type structure development is to define the path of control transfer on each stage of continuous cast billet production. Taking into account the fact that each kind of defects can be formed on each production stage with different probability, it was decided to develop a fuzzy decision tree.

The attributes of the tree are the values of metrological parameters of production units of the processing chain. The list of the used parameters is given in the table.

Table: The List of Attributes Defining the Structure of the Adaptive Fuzzy Decision Tree with Dynamic Structure

\begin{tabular}{|c|l|c|}
\hline Production unit & \multicolumn{1}{|c|}{ Attribute } & Value range \\
\hline \multirow{4}{*}{ Arc steel-making furnace } & Content of chemical elements in burden materials, \% & Percentage \\
\cline { 2 - 3 } & Content of chemical elements in steel after tapping, \% & Percentage \\
\cline { 2 - 3 } & Weight of lump ferroalloys, $\mathrm{kg}$ & $250-4500$ \\
\cline { 2 - 3 } & Weight of supplementary materials, $\mathrm{kg}$ & $5000-10000$ \\
\cline { 2 - 3 } & Weight of carbon-bearing materials, $\mathrm{kg}$ & $100-1500$ \\
\cline { 2 - 3 } & Weight of liquid iron in the ladle, $\mathrm{t}$ & $10-80$ \\
\hline \multirow{5}{*}{ Ladle furnace } & Content of chemical elements in steel, \% & Percentage \\
\cline { 2 - 3 } & Metal temperature after refining, ${ }^{\circ} \mathrm{C}$ & $1500-1700$ \\
\cline { 2 - 3 } & Argon consumption for blowing, $\mathrm{m}^{3} / \mathrm{h}$ & $0-72$ \\
\cline { 2 - 3 } & Weight of added aluminum wire rod, $\mathrm{kg}$ & $1-1500$ \\
\hline \multirow{3}{*}{ Billet continuous casting machine } & Metal temperature in the tundish, ${ }^{\circ} \mathrm{C}$ & $1-5$ \\
\cline { 2 - 3 } & Billet withdrawal rate, $\mathrm{m} / \mathrm{min}$ & $4,8-5,5$ \\
\cline { 2 - 3 } & Water consumption rate on the wide mold walls, $\mathrm{m}^{3} / \mathrm{min}$ \\
\hline
\end{tabular}

\section{MATHEMATICAL BASICS OF THE ADAPTIVE FUZZY DECISION TrEe WITH DYNAMIC STRUCTURE}

Common algorithm $\mathrm{C} 4.5[8,9]$ is used in the paper to develop decision trees. Adequate decision making by means of fuzzy trees is based on the membership functions of the example in the value set of each attribute. The authors suggest that expert knowledge should be used to develop membership functions of the attributes described above. The graph of membership function of defect size to three values is given in Fig. 1.

After developing a fuzzy decision tree according to $\mathrm{C} 4.5$ algorithm, using membership function and training examples the authors cut brunches leading to erroneous decisions and test the obtained tree on the correctness of decision making [10]. Testing is carried out using the model sampling of examples.

\section{ADAPTATION Algorithm AND DYNAMICS OF FUZZY DECISION TREE STRUCTURE}

After each estimation of continuous cast billet macrostructure the initial data forming the tree is supplemented by new information and on the basis of this information the process of adaptation of calculated values of the tree model parameters is carried out (Fig. 2). Because of the changes in parameters the tree model can also change its structure. After the changes the tree is tested on adequacy. The obtained tree adapts better to the updated technological conditions. The dynamic nature of the structure makes it possible to estimate the real value of each attribute in the process of continuous cast billet production. The example of the possible hierarchy of an adaptive fuzzy decision tree with dynamic structure is given in Fig. 3.

Efficient parameters of production units control are defined in the process of moving along the tree from the leaf to the root with obtaining a qualitative assessment (Fig. 4).

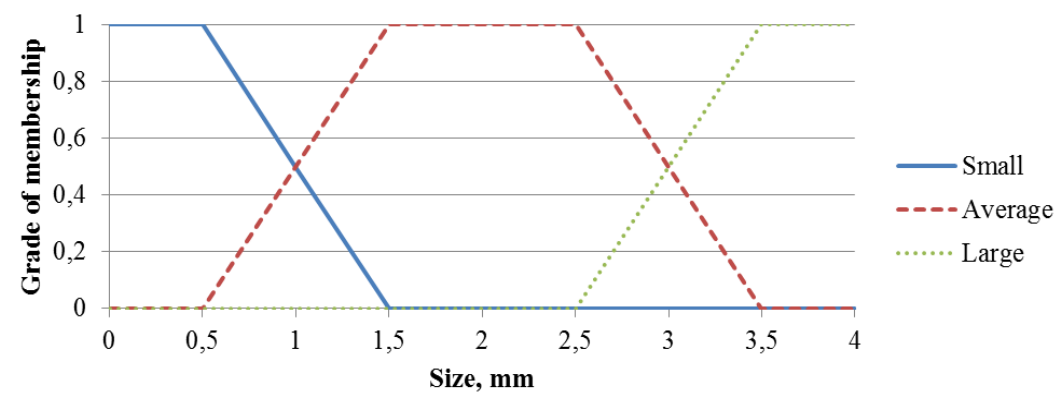

Fig. 1. The Graph of Membership Function of Defect Size 


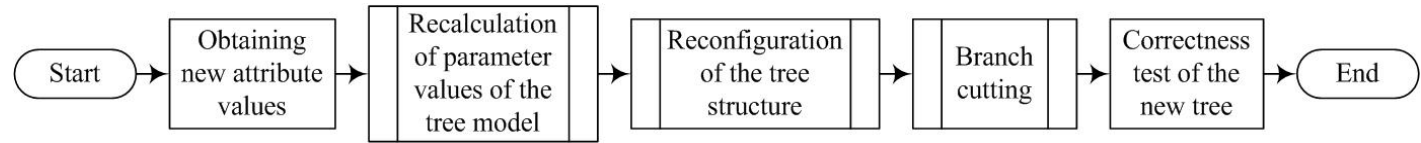

Fig. 2. Algorithm of Additional Learning and Reconfiguration of the Adaptive Fuzzy Decision Tree with Dynamic Structure

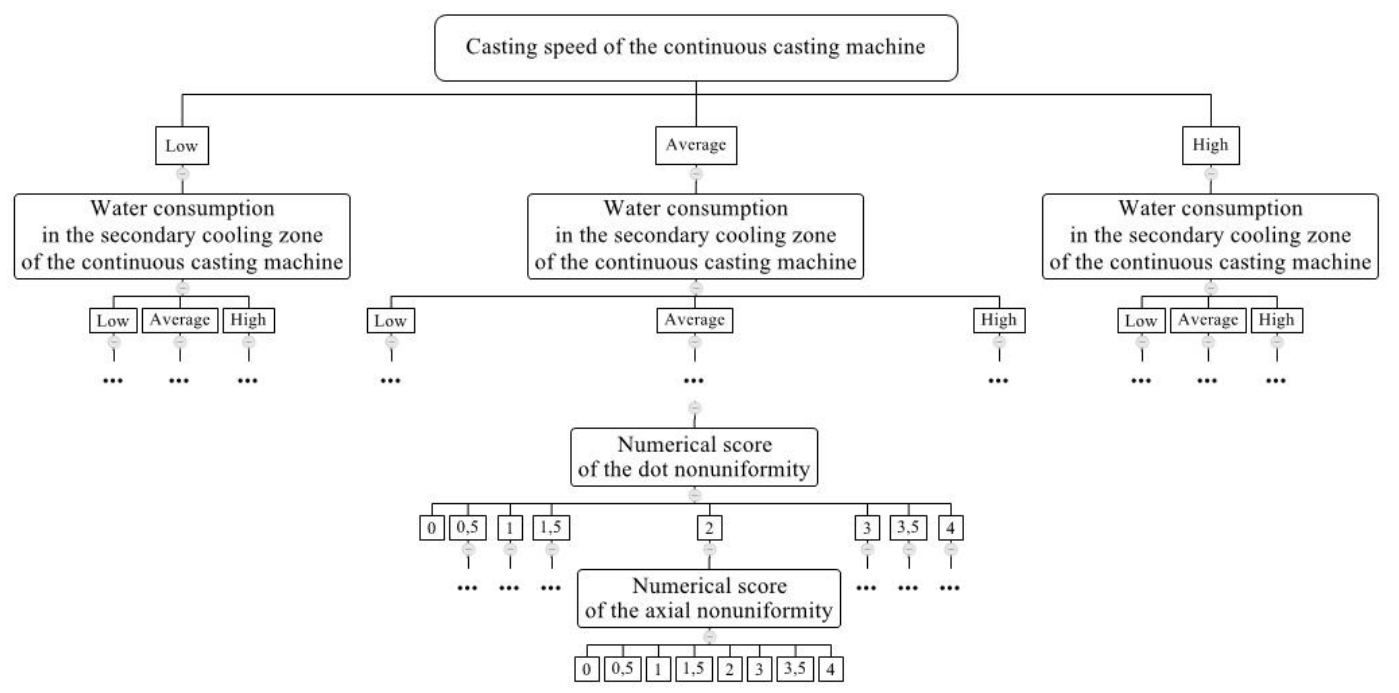

Fig. 3. Hierarchy of an adaptive fuzzy decision tree with dynamic structure

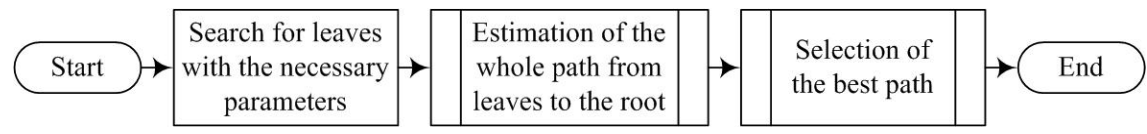

Fig. 4. Algorithm of Parameters Selection in the Adaptive Fuzzy Decision Tree with Dynamic Structure

\section{Conclusion}

Thus, in this paper the authors managed to:

- prove that it is necessary to provide feedback for automatic control system of continuous cast billet production, making it possible to correct the technology of batch production on a real time basis;

- determine the structure of adaptive fuzzy decision tree with dynamic structure taking into account the set of available metrological equipment which makes it possible to provide control action on the ongoing process;

- develop adaptation algorithm and dynamics of fuzzy decision tree structure making it possible to perform software implementation of the module for the decision-making block of the cascade automatic control system of continuous cast billet production.

\section{Acknowledgements}

This study was subsidized by the grants of Government of Chelyabinsk region (2011 - 2012 years) and Federal State Budgetary Educational Institution of Higher Professional Education "Magnitogorsk state technical university named after G.I. Nosov".

\section{REFERENCES}

[1] N.A. Spirin, V.V. Lavrov, Information systems in metallurgy: Lectures (Yekaterinburg: Ural state technical university, 2004) 495.

[2] D. Bobrovsky, An introduction to the theory of dynamic systems with discrete time (St. Petersburg: Regular and chaotic dynamics, 2006) 360.

[3] O.S. Logunova, System approach to the study of data flows in the process of product quality control, Problems of control theory and practice, 6, 2008, 56-63.

[4] O.S. Logunova, The study of qualitative relationship between internal defects formation and thermal state of the continuous cast billet, Steel, 10, 2008, 60-63.

[5] Y.N. Lvovsky, Statistical methods of empirical equations development: Tutorial for technical universities (Moscow: High School, 1998) 239.

[6] T. Hastie, R. Tibshirani, J. Friedman, The Elements of Statistical Learning: Data Mining, Inference and Prediction (New York: Springer Science + Business Media, 2009) 746 .

[7] A. Shahidi, Decision trees - general principles of operation, http://www.basegroup.ru/library/analysis/tree/description/

[8] J.R. Quinlan, C4.5: Programs for Machine Learning (San Mateo: Morgan Kaufmann Publishers Inc., 1993) 302.

[9] C.Z. Janikow, Fuzzy Decision Trees: Issues and Methods, IEEE Trans Syst Man Cybern, 1998, 1-14.

[10] O.G. Berestneva, E.A. Muratova, Logical models development using decision trees, Proceedings of Tomsk polytechnic university, 2(307), 2004, 154-160. 